\title{
A randomized trial to determine the impact of indacaterol/glycopyrronium on nighttime oxygenation and symptoms in patients with moderate-to-severe COPD: the DuoSleep study
}

This article was published in the following Dove Medical Press journal:

International Journal of COPD

\author{
Sverre Lehmann ${ }^{1,2}$ \\ Thomas Ringbæk ${ }^{3}$ \\ Anders Løkke ${ }^{4}$ \\ Ludger Grote ${ }^{5}$ \\ Jan Hedner 6 \\ Eva Lindberg ${ }^{7}$
}

'Department of Thoracic Medicine, Norwegian Competence Center for Sleep Disorders, Haukeland University Hospital, Bergen, Norway; ${ }^{2}$ Section of Thoracic Medicine, Department of Clinical Science, University of Bergen, Bergen, Norway; ${ }^{3}$ Department of Pulmonary Medicine, Hvidovre Hospital, University of Copenhagen, Denmark; ${ }^{4}$ Department of Respiratory Diseases and Allergy, Aarhus University Hospital, Aarhus, Denmark; ${ }^{5}$ Sleep Disorders Center, Department of Respiratory Medicine, Sahlgrenska University Hospital, Gothenburg, Sweden; ${ }^{6}$ Department of Internal Medicine, Center for Sleep and Wake Disorders, University of Gothenburg and Pulmonary Medicine, Sahlgrenska University Hospital, Gothenburg, Sweden; ${ }^{7}$ Department of Medical Sciences, Respiratory, Allergy and Sleep Research, Uppsala University, Uppsala, Sweden

Correspondence: Sverre Lehmann Norwegian Competence Center for Sleep Disorders, Haukeland University Hospital, Jonas Lies vei $65, \mathrm{~N}-502$ I

Bergen, Norway

Tel +47559732 49

Fax +4755975। 49

Email sverre.lehmann@helse-bergen.no
Purpose: This study investigated the effect of dual bronchodilation with the long-acting $\beta$-receptor agonist/long-acting muscarinic antagonist combination, indacaterol/glycopyrronium (IND/GLY), on nighttime oxygenation, lung function, sleep quality, and symptoms in patients with moderate-to-severe COPD.

Patients and methods: This was a 4-week, double-blind, multicenter, placebo-controlled, twoperiod crossover study. Patients were randomized in a 1:1 ratio to receive IND/GLY 110/50 $\mu \mathrm{g}$ once daily or matching placebo. The primary objective was to evaluate the effect of treatment with IND/GLY on mean nighttime oxygenation, compared with placebo. The secondary objective was to determine the time spent $<90 \%$ in blood oxygen saturation $\left(\mathrm{SpO}_{2}\right)$ compared with placebo. Exploratory objectives were to assess the effect of IND/GLY, compared with placebo, on sleep quality measured by the Medical Outcomes Study (MOS) Sleep Scale and the COPD and Asthma Sleep Impact Scale (CASIS) questionnaires and on symptoms assessed by COPD Assessment Test (CAT) questionnaire.

Results: In total, 38 patients were randomized ( $n=22$, IND/GLY; $n=16$, placebo). The change in nighttime oxygenation $\left(\mathrm{SpO}_{2}\right)$ was similar, and there was a comparable difference in time spent $<90 \% \mathrm{SpO}_{2}$ between IND/GLY and placebo. Increases from baseline for the difference between IND/GLY and placebo for trough $\mathrm{FEV}_{1}, \mathrm{FVC}$, and inspiratory capacity $(P<0.05)$ were seen, with a corresponding reduction in residual volume and functional residual capacity $(P<0.05)$. IND/GLY treatment showed an improvement in scores for CAT $(P=0.0208)$, CASIS, and the MOS Sleep Scale measures, Sleep Problems Index I, Sleep Problems Index II $(P=0.0315)$, Sleep Adequacy, Sleep Disturbance Scale, Somnolence Scale, and Short of Breath Scale $(P=0.0031)$.

Conclusion: In this study, IND/GLY $110 / 50 \mu \mathrm{g}$ once daily improved symptoms, sleep quality, and lung function, but showed no effect on nighttime oxygenation in patients with moderateto-severe COPD.

Keywords: bronchodilator, sleep, hypoxia, quality of life, lung function

\section{Introduction}

Sleep disturbances and nighttime symptoms are frequently experienced by patients with respiratory diseases. ${ }^{1-3}$ Patients with COPD report poorer quality of sleep than those of a similar age without COPD. ${ }^{4}$ While epidemiological studies suggest that at least $75 \%$ of patients with COPD experience nocturnal symptoms and symptomatic sleep disturbance, physicians are often unaware of these, because they go unreported 
by patients. ${ }^{5}$ In a recent survey, $61 \%$ of patients with COPD reported both nighttime and early morning symptoms, most frequently coughing, wheezing, and shortness of breath. Of those with nighttime symptoms, $77.7 \%$ reported slightto-extreme sleep disturbances, $34.4 \%$ reported awakening at least once each night, and $25.3 \%$ reported difficulty falling asleep. ${ }^{6}$ More than $50 \%$ of patients in the Subpopulations and Intermediate Outcome Measures in COPD Study, a large COPD cohort study, reported poor sleep quality, and sleep quality was a significant predictor of the quality of life. ${ }^{7,8}$

When patients with COPD experience hypoxia during the night, it frequently appears as prolonged oxygen desaturations during rapid eye movement (REM) sleep. ${ }^{9}$ Nighttime hypoxia may be a problem even in patients without significant daytime hypoxia. ${ }^{10}$ Several mechanisms including gas exchange alterations, lung volume alterations, reduced respiratory effort, and ventilation-perfusion $(\mathrm{V} / \mathrm{Q})$ mismatch are involved in sleep-related breathing disorders and hypoxemia in patients with COPD. ${ }^{11}$

Progressive airflow limitation and destruction of the pulmonary capillary bed in patients with COPD result in $\mathrm{V} / \mathrm{Q}$ mismatch. ${ }^{2}$ The reduction in functional residual capacity (FRC) which occurs during sleep, as well as the reported $10 \%$ decrease in FRC associated with a supine position, may add to V/Q mismatch in patients with COPD, ${ }^{12,13}$ leading to lower oxygen reserves. ${ }^{3}$ Decreased mucociliary clearance in patients with COPD while sleeping may cause worsening of $\mathrm{V} / \mathrm{Q}$ mismatch. ${ }^{3}$ The progression of COPD to its end stages of severe hypoxemia, right heart failure, and death may be dependent upon the severity of desaturation occurring during sleep. ${ }^{14-17}$
Patients treated with the long-acting muscarinic antagonist (LAMA) tiotropium showed significant improvements in sleep arterial oxygen saturation $\left(\mathrm{SaO}_{2}\right)$ compared with placebo, especially during REM sleep. However, there was no improvement in sleep quality, measured by either polysomnography or patients' subjective perception, or daytime sleepiness assessed by the Epworth Sleepiness Scale (ESS) score. ${ }^{18}$ A study of the long-acting $\beta$-receptor agonist (LABA) salmeterol showed similar results: $\mathrm{SaO}_{2}$ and the percentage of sleep spent $<90 \%$ in oxygenation improved significantly in patients with COPD treated with salmeterol, compared with placebo; however, there was no concomitant improvement in sleep quality. ${ }^{19}$

Dual bronchodilation with the fixed LABA/LAMA combination indacaterol/glycopyrronium(IND/GLY) improves lung function and reduces exacerbations more than either of its components, or open-label tiotropium, ${ }^{20,21}$ or the combination of salmeterol and fluticasone in patients with COPD. ${ }^{22,23}$ Given that a considerable degree of symptoms, including potential hypoxemia, in COPD may be confined to the sleeping period, it was hypothesized that induction of optimal dual bronchodilation would increase nocturnal oxygenation and improve sleep quality and COPD symptoms. The aim of this study was to investigate the effect of IND/GLY $110 / 50 \mu \mathrm{g}$ once daily on nighttime oxygenation, lung function, sleep quality, and symptoms in patients with moderate-to-severe COPD.

\section{Patients and methods}

\section{Study design}

This was a randomized, double-blind, multicenter, placebocontrolled, two-period crossover study (Figure 1). From

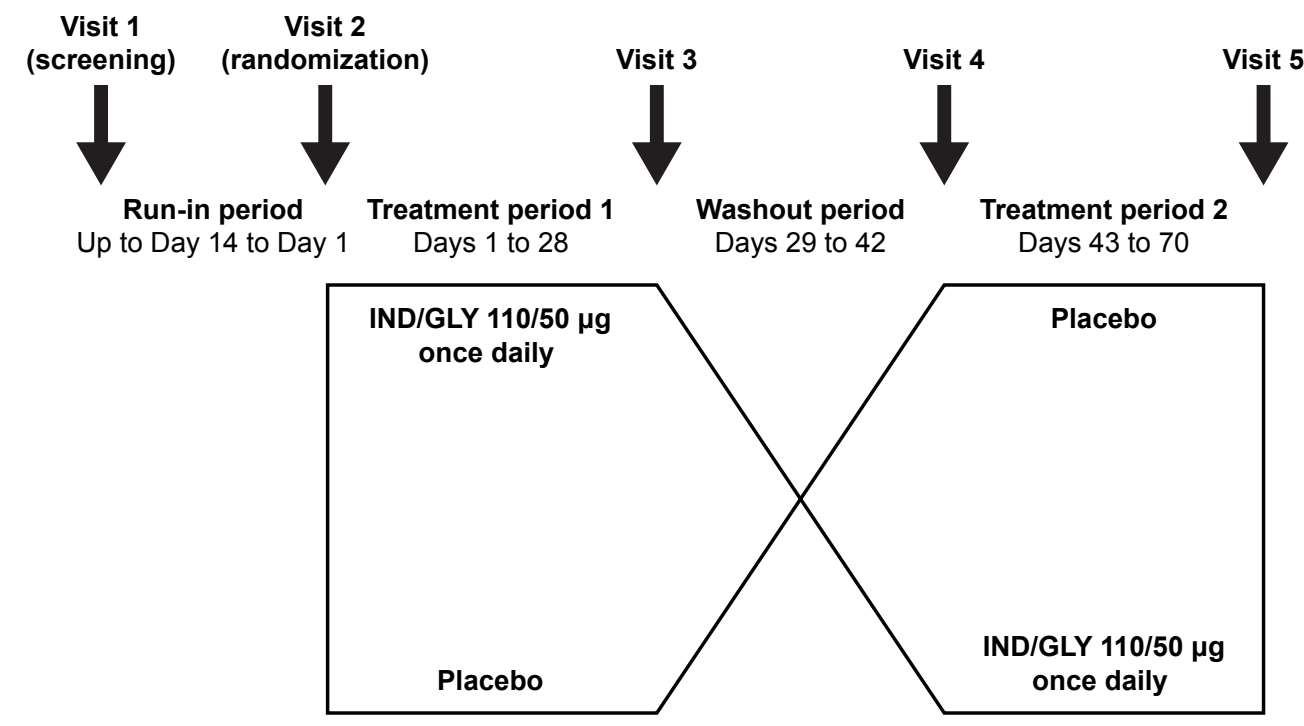

Figure I Study design.

Abbreviation: IND/GLY, indacaterol/glycopyrronium. 
November 2014 through June 2016, patients were enrolled at five sites across Norway, Sweden, and Denmark. Each screening visit was followed by a run-in period of up to 14 days, dependent on COPD therapy, before randomization.

Patients were randomized in a 1:1 ratio to initially receive IND/GLY 110/50 $\mu \mathrm{g}$ (Novartis Pharma AG, Basel, Switzerland) once daily or matching placebo. Both treatment periods were of 4 weeks' duration, with a 2-week washout period in between. Patients took their usual short-acting $\beta_{2}$-agonists (SABA) as rescue medication on an "as-needed" basis throughout the study. Patients who were being treated with an inhaled corticosteroid (ICS) plus an LABA discontinued this treatment and were instead prescribed ICS monotherapy at an equivalent dose and dosing regimen for the duration of the study.

The trial was approved by the Independent Ethics Committee at each trial site. The study was registered at ClinicalTrials.gov (Identifier Number: NCT02233543) and was conducted according to the ethical principles of the Declaration of Helsinki. Informed consent was obtained from each patient in writing before conducting any studyspecific procedures.

\section{Participants}

The study enrolled patients aged $\geq 40$ years, with resting daytime oxygen saturation $\left(\mathrm{SpO}_{2}\right)$, as measured by pulse oximetry, of $\leq 95 \%$, a post-bronchodilator $\mathrm{FEV}_{1} \geq 30 \%$ and $<60 \%$ of the predicted normal value, and a clinical diagnosis of COPD (according to the GOLD 2014) with a post-bronchodilator $\mathrm{FEV}_{1} / \mathrm{FVC}<0.70$. All the participants were current or ex-smokers who had a smoking history of at least 10 pack-years. Significant sleep apnea, defined as an Apnea-Hypopnea Index of $\geq 15$ events/hour, constituted an exclusion criterion. Full details of inclusion and exclusion criteria are listed in the Supplementary materials.

\section{Objectives and efficacy assessments}

The primary objective of this study was to evaluate the effect of 4 weeks of treatment with IND/GLY on mean nighttime oxygenation in patients with moderate-to-severe COPD compared with placebo. The secondary objective was to determine the time spent at $<90 \%$ in blood oxygen saturation $\left(\mathrm{SpO}_{2}\right)$ compared with placebo in these patients. One exploratory objective was to assess the lung function and lung volumes after 4 weeks' administration of IND/GLY, compared with placebo, measured in the morning prior to drug administration using plethysmography and diffusing capacity of the lung for carbon monoxide (DLCO) measures: trough FEV
$\left(\mathrm{tFEV}_{1}\right), \mathrm{FVC}$, total lung capacity, FRC, residual volume, inspiratory capacity (IC), DLCO, and DLCO divided by the volume of the alveolar (DLCO/VA). A second exploratory objective was to assess the effect of IND/GLY, compared with placebo, on sleep quality measured by the Medical Outcomes Study (MOS) Sleep Scale ${ }^{24}$ and the COPD and Asthma Sleep Impact Scale (CASIS) questionnaires ${ }^{7}$ and on symptoms assessed by COPD Assessment Test (CAT) questionnaire. ${ }^{25}$

Nighttime oxygenation $\left(\mathrm{SpO}_{2}\right)$ was measured using respiratory polygraphy at home over two consecutive nights prior to visits 2, 3, 4, and 5. All the patients used an Embletta ${ }^{\circledR}$ (Stowood, Oxford, UK) or NOX-T3 ${ }^{\circledR}$ (Nox Medical, Reykjavík, Iceland) polygraph for the measurement of $\mathrm{SpO}_{2}$ at night. Data collected during the polygraphy recording were stored in a computer and subsequently transferred to a database for a centralized analysis procedure. The polygraphy expert, who was blinded for patient information, documented the $\mathrm{SpO}_{2}$ results in the electronic case report forms (eCRFs). To support the evaluation of the polygraph data, the patients recorded information in a night report, including bedtime and wake-up time, the number of times the patient had left the bed during the night, and the use of rescue medication. Time spent in an upright position and time reported as awake time by the patient were excluded from the polygraph analyses. Data from the second night were applied in the analyses (to avoid a "first night effect") if judged as technically acceptable by the sleep technician, who was blinded for the patient treatment randomization. Time spent $<90 \%$ in $\mathrm{SpO}_{2}$ was calculated based on the $\mathrm{SpO}_{2}$ data recorded by polygraphy during the night.

Body plethysmography and DLCO measurements were taken according to the recommendations of the American Thoracic Society/European Respiratory Society Task Force on standardization of lung function testing, using the spirometric prediction equation standards for the European Community for Coal and Steel. ${ }^{26,27}$ At sites where plethysmography was performed, the patients were instructed to withhold the use of SABA (rescue medication) for at least 6 hours before all clinic visits, unless the use was absolutely necessary. Furthermore, the patients at these sites were asked to take study drugs in the morning between 08:00 and 09:00 on the day before clinic visits, to ensure that at least 24 hours had passed from last study drug intake to plethysmography measurements.

The patients completed the MOS Sleep Scale (a selfadministered questionnaire with 12 questions on different dimensions of sleep), CASIS (a patient-reported measure to assess the impact on sleep due to respiratory disease), 
and CAT questionnaire (a short instrument used to quantify the symptom burden of COPD and assess the health status of patients) before any study-related procedures were conducted at visits 2, 3, 4, and 5. One experienced sleep technician scored the sleep recordings from all sites throughout the study.

\section{Safety assessments}

Safety assessments consisted of collecting all adverse events (AEs), serious AEs (SAEs), with their severity and relationship to study drug, and pregnancies. All AEs were recorded using an eCRF for all patients included in the safety analysis.

\section{Statistical analysis}

The safety set population consisted of patients who received at least one dose of one of the study treatments. The full analysis set (FAS) population consisted of patients who were included in the safety set population and had at least one assessment of the primary and/or secondary efficacy variables.

Patient demographics and baseline characteristics were presented using summary statistics. Preplanned, statistical hypothesis tests were performed for the primary and secondary objectives, nighttime oxygenation, and time spent $<90 \%$ in $\mathrm{SpO}_{2}$ after 4 weeks of treatment, while other exploratory endpoints were generally presented using summary statistics.

Post hoc analyses were carried out for the exploratory variables: lung function analyses, MOS Sleep Scale, CASIS, and CAT. The treatment comparisons between IND/GLY and placebo were analyzed by mixed model with period and treatment as fixed effects, baseline as a covariate effect, and subject as a random effect. Based on this model, two-sided tests were performed using a $5 \%$ level of significance, and a 95\% two-sided CI for the estimated difference in least square means was presented. The exploratory variable Optimal Sleep Scale (part of the MOS Sleep Scale) was analyzed by binomial model including period, baseline, and actual treatment as fixed effects and patient as a random effect.

A post hoc logistic regression analysis was carried out for change in $\mathrm{SpO}_{2}$ above or below specific cutoff points $\left(\mathrm{SpO}_{2} \geq-1 ; \mathrm{SpO}_{2} \geq-2 ; \mathrm{SpO}_{2} \geq 1 ; \mathrm{SpO}_{2} \geq 1\right.$ vs $\leq-1 ; \mathrm{SpO}_{2} \geq 2 ;$ $\mathrm{SpO}_{2} \geq 2$ vs $\leq-2$ ) during treatment periods. The following were covariates in the analysis: age, body mass index, daytime oxygen saturation, DLCO, DLCO/VA; $\mathrm{FEV}_{1} \%$ of predicted normal, $\mathrm{FEV}_{1}$, sex; and total CAT score. The last available measurements before the first treatment were used for each covariate. The model included baseline $\mathrm{SpO}_{2}$, treatment period, the relevant covariate, and its corresponding interaction with treatment, with the patient as a random effect.

\section{Sample size calculation}

For the crossover design, a paired $t$-test was used for the sample size calculation with a mean difference of $2, \mathrm{SD}$ of 3.8, and a significance level of 0.05 . A $\Delta$ of 2 (change in nighttime oxygenation in percent) was chosen, based upon the effect seen with long-acting bronchodilators in monotherapy. With a correlation coefficient of 0.3 or 0.6 , the number of patients needed to ensure $80 \%$ power would have been 42 or 26, respectively. With a $\Delta$ of 2,26 of 50 patients would have been needed to complete the study to maintain $80 \%$ power (equal to a dropout rate of $48 \%$ ). Thus, with 50 patients included, it was expected that a sufficient number of patients would complete the trial to allow credible statistical analyses of the data collected.

\section{Results Study participants}

In total, 71 patients were screened. During the run-in period, 5 patients discontinued the study and 38 patients were randomized initially to receive IND/GLY or placebo ( $n=22$ IND/ GLY; $n=16$ placebo). Both the FAS population and safety set consisted of 38 patients. Figure 2 shows the reasons for discontinuation during the screening, run-in, and treatment periods.

Patient demographics and baseline characteristics were balanced between the two treatment groups (Table 1). The mean age in the safety population was 68.4 years with a range of 55-81 years. Twenty-one patients were diagnosed with COPD before 2010 . Approximately $66 \%$ of patients did not experience an exacerbation during the previous 12 months. The $\mathrm{SpO}_{2}$ at baseline for all the patients was $\leq 95 \%$ as defined by the inclusion criterion; the lowest result reported was $89 \%(n=1)$, and the highest was $95 \%(n=12)$.

\section{Efficacy outcomes}

The primary efficacy analysis showed that the change in nighttime oxygenation $\left(\mathrm{SpO}_{2}\right)$ was similar $(P=0.2419)$ between IND/GLY and placebo after 4 weeks of treatment for the FAS population (Table 2; Figure 3). A high degree of interindividual variability was seen (Figure 3). Likewise, the secondary analysis also showed a comparable difference in time spent $<90 \%$ in $\mathrm{SpO}_{2}$ between IND/GLY and placebo $(P=0.2016)$. The logistic regression analysis showed that none of the covariates evaluated were significantly associated with the change from baseline in $\mathrm{SpO}_{2}$ at any of the cutoff points assessed ( $P>0.05$ for all comparisons). 


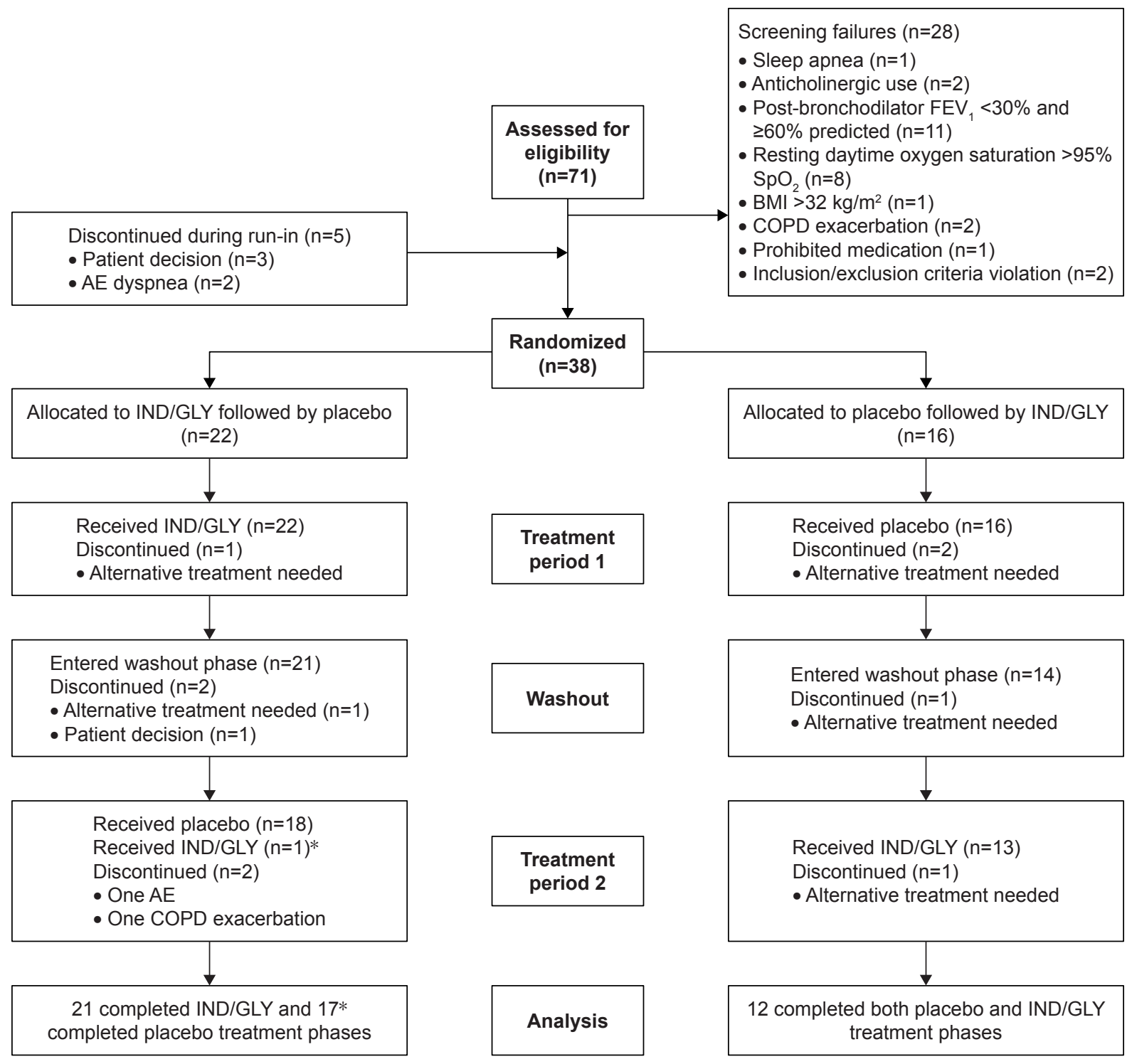

Full analysis set $(n=38)$

IND/GLY ( $n=35$; treatment period $1 ; n=22$; treatment period $2 ; n=13)$

Placebo ( $n=34$; treatment period $1 ; n=16$; treatment period $2 ; n=18$ )

Figure 2 Trial profile.

Notes: *One patient was randomized to receive ING/GLY in Period I, but received placebo in error. The patient received placebo for one week in Period 2 and then IND/ GLY for four weeks.

Abbreviations: AE, adverse event; $\mathrm{BMI}$, body mass index; IND/GLY, indacaterol/glycopyrronium; $\mathrm{SpO}_{2}$, blood oxygen saturation.

The analysis of lung function parameters showed positive changes from baseline for the difference between IND/ GLY and placebo for tFEV ${ }_{1}, \mathrm{FVC}$, and IC $(P<0.05)$ and a corresponding negative change in residual volume and FRC $(P<0.05$; Table 3$)$. No differences were seen in diffusion capacity between IND/GLY and placebo treatment.

After 4 weeks of treatment, there was an improvement in mean (SD) CAT total score from baseline for IND/GLY $(-1.5$ [3.5]; negative score indicates improvement), while the change was positive for placebo (1.2 [5.2]; ie, disimprovement). The treatment difference in change from baseline mean (SD) was -3.1 (6.5). Least squares (LS) means analysis showed a treatment difference of $-2.56(-4.72,-0.40)$, $P=0.0208$ in favor of IND/GLY (Table 4).

Mean (SD) CASIS total score slightly improved from baseline for both treatments $(-0.2$ [2.5] for IND/GLY and -0.2 [2.7] for placebo; negative score indicates improvement), but the treatment difference was not statistically 
Table I Patient demographics and baseline characteristics

\begin{tabular}{|c|c|c|c|}
\hline Characteristics & $\begin{array}{l}\text { IND/GLY-placebo } \\
(n=22)\end{array}$ & $\begin{array}{l}\text { Placebo-IND/GLY } \\
(n=16)\end{array}$ & $\begin{array}{l}\text { Total } \\
(\mathbf{N}=\mathbf{3 8})\end{array}$ \\
\hline Age (years) & $68.0(7.3)$ & $69.0(4.6)$ & $68.4(6.2)$ \\
\hline Male sex, n (\%) & $14(63.6)$ & $10(62.5)$ & $24(63.2)$ \\
\hline BMI $\left(\mathrm{kg} / \mathrm{m}^{2}\right)$ & $25.5(3.5)$ & $24.6(4.2)$ & $25.1(3.8)$ \\
\hline $\begin{array}{l}\text { COPD exacerbation history (pre } \\
\text { No exacerbations } \\
\geq \text { I exacerbation/second }\end{array}$ & $\begin{array}{l}14(63.6) \\
8(36.4)\end{array}$ & $\begin{array}{l}\text { II (68.8) } \\
5(31.3)\end{array}$ & $\begin{array}{l}25(65.8) \\
13(34.2)\end{array}$ \\
\hline $\begin{array}{l}\text { Smoking history } \\
\text { Total pack-years }\end{array}$ & $42.9(26.7)$ & $34.6(13.3)$ & $39.4(22.2)$ \\
\hline $\mathrm{FEV}_{1}(\mathrm{~L})$ & $\mathrm{I} .44(0.42)$ & $1.21(0.25)$ & $1.34(0.37)$ \\
\hline $\mathrm{FEV}_{1} \%$ of predicted normal (\%) & $47.83(7.01)$ & $44.94(7.73)$ & $46.61(7.36)$ \\
\hline $\mathrm{FVC}(\mathrm{L})$ & $3.20(0.94)$ & $3.15(0.77)$ & $3.18(0.86)$ \\
\hline $\mathrm{FEV}_{1} / \mathrm{FVC}$ & $0.46(0.07)$ & $0.40(0.09)$ & $0.43(0.08)$ \\
\hline Daytime $\mathrm{SaO}_{2}(\%)$ & $90.4(20.6)$ & $88.4(23.4)$ & $89.5(21.5)$ \\
\hline $\mathrm{PaO}_{2}(\mathrm{kPa})$ & $9.6(1.5)$ & $9.3(1.0)$ & $9.5(1.3)$ \\
\hline $\mathrm{HCO}_{3}(\mathrm{mmol} / \mathrm{L})$ & $25.6(1.7)$ & $24.2(6.1)$ & $25.0(4.2)$ \\
\hline
\end{tabular}

Note: Values are mean \pm SD unless specified.

Abbreviations: $\mathrm{BMI}$, body mass index; $\mathrm{HCO}_{3}$, bicarbonate in blood; IND/GLY, indacaterol/glycopyrronium; $\mathrm{PaO}$, partial pressure of oxygen in arterial blood; SaO , oxygen saturation.

significant $(-0.4[2.8]$, LS means $-0.02[-1.03,1.00]$, $P=0.9724$; Table 4).

For the MOS Sleep Scale, there was an improvement from baseline mean (SD) total score for IND/GLY for the following sleep scale scores (negative score indicates improvement): Sleep Problems Index I (-3.55 [11.25]), Sleep Problems Index II (-3.17 [9.14]), Sleep Disturbance Scale $(-2.39$ [10.85]), Sleep Quantity ( -0.05 [0.68]), Somnolence Scale ( -1.29 [14.75]), and Short of Breath Scale (-6.45 [14.04]). For placebo, an improvement was seen for Sleep
Problem Index I (-0.11 [8.42]), Sleep Quantity -0.08 [0.51], and Snoring scale 0.71 [19.23]. LS means analysis showed that the treatment differences were significant for Sleep Problems Index II and Short of Breath scale (Table 4).

\section{Safety outcomes}

Forty-one AEs were reported, of which 24 were for IND/GLY treatment and 17 for placebo. Twelve AEs were assessed as related to either the investigational or other treatment: five for IND/GLY treatment and seven for placebo treatment.

Table 2 Change in nighttime oxygenation and time spent $<90 \%$ in $\mathrm{SpO}_{2}$ in patients treated with IND/GLY and placebo (full analysis set)

\begin{tabular}{|c|c|c|c|c|c|c|}
\hline \multirow{2}{*}{$\begin{array}{l}\text { Nighttime oxygenation } \\
\text { measures }\end{array}$} & \multicolumn{2}{|c|}{ Observed values (\%) } & \multicolumn{2}{|l|}{ LS means } & \multicolumn{2}{|l|}{ LS means $(95 \% \mathrm{Cl})$} \\
\hline & $\begin{array}{l}\text { IND/GLY } \\
(\mathbf{N}=35)\end{array}$ & $\begin{array}{l}\text { Placebo } \\
(\mathbf{N}=34)\end{array}$ & $\begin{array}{l}\text { IND/GLY } \\
(\mathbf{N}=35)\end{array}$ & $\begin{array}{l}\text { Placebo } \\
(\mathbf{N}=34)\end{array}$ & $\begin{array}{l}\text { Difference }{ }^{\mathrm{a}} \text { IND/ } \\
\text { GLY-placebo }\end{array}$ & $P$-value \\
\hline \multicolumn{7}{|c|}{ Nighttime (mean $\pm \mathrm{SD}$ ) oxygenation $\mathrm{SpO}_{2}$} \\
\hline Baseline (visit 2 or 4 ) & $89.73 \pm 2.08$ & $89.87 \pm 1.70$ & - & - & - & - \\
\hline Posttreatment (visit 3 or 5 ) & $89.61 \pm 2.12$ & $89.97 \pm 2.02$ & $89.59 \pm 0.30$ & $90.04 \pm 0.28$ & - & - \\
\hline Treatment difference & - & - & - & - & $-0.44(-1.21,0.32)$ & 0.2419 \\
\hline \multicolumn{7}{|c|}{ Time $(\% \pm \mathrm{SD})$ spent $<90 \%$ in $\mathrm{SpO}_{2}$} \\
\hline Baseline (visit 2 or 4 ) & $43.48 \pm 37.21$ & $38.8 I \pm 32.74$ & - & - & - & - \\
\hline Posttreatment (visit 3 or 5 ) & $43.75 \pm 35.26$ & $37.59 \pm 31.45$ & $44.37 \pm 5.09$ & $36.58 \pm 4.84$ & - & - \\
\hline Treatment difference & - & - & - & - & $7.79(-4.5 \mathrm{I}, 20.08)$ & 0.2016 \\
\hline
\end{tabular}

Notes: LS-means analysis was carried out using a mixed Model including period and actual treatment as fixed effects, baseline as covariate and subject effect as random. ${ }^{a}$ Only includes patients with data from both treatments.

Abbreviations: IND/GLY, indacaterol/glycopyrronium; LS, least squares; $\mathrm{SpO}_{2}$, oxygen saturation. 

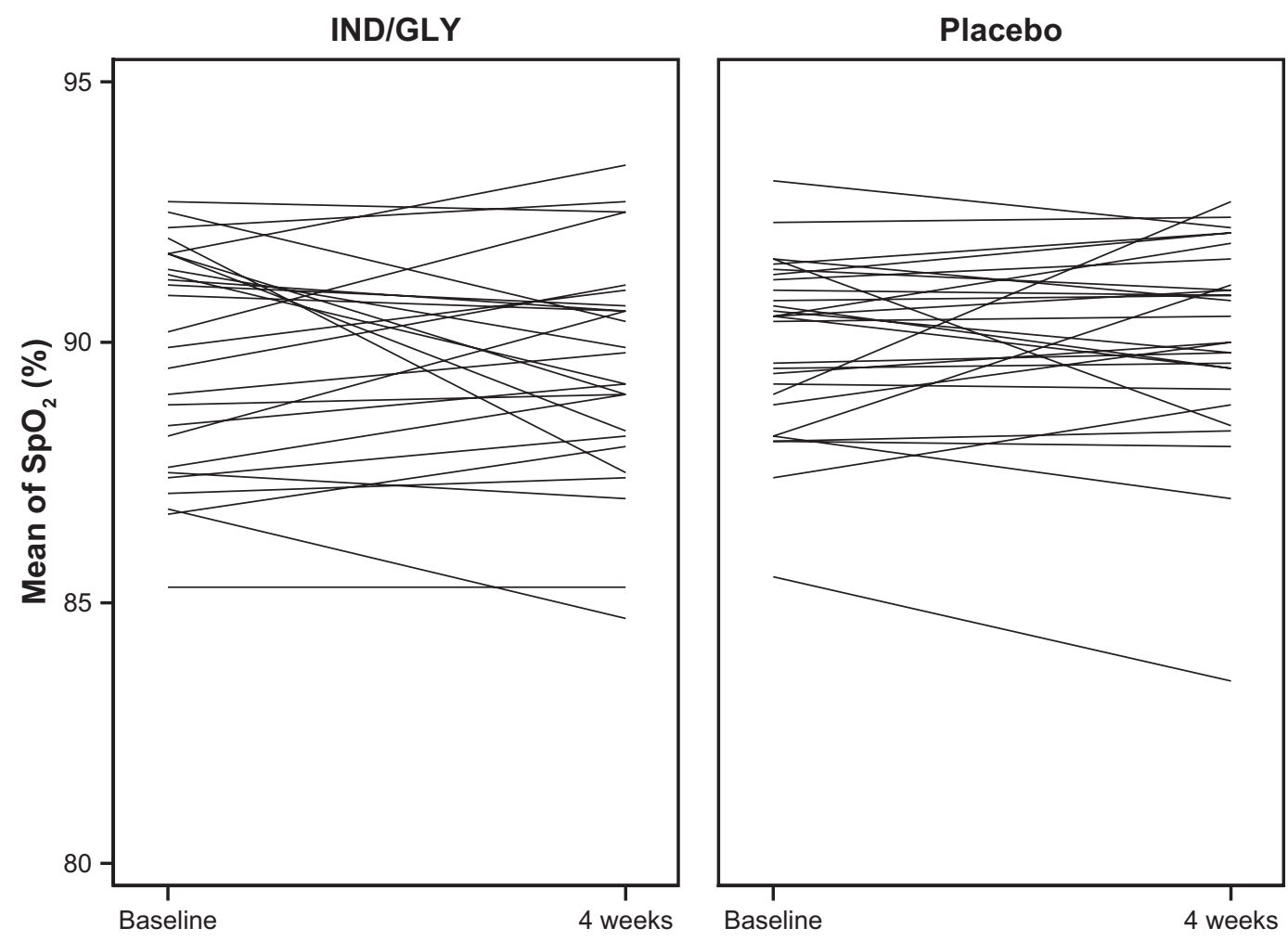

Figure 3 Mean nighttime blood oxygen saturation $\left(\mathrm{SpO}_{2}\right)$ using respiratory polygraphy (full analysis set) at baseline and week 4.

Abbreviation: IND/GLY, indacaterol/glycopyrronium.

The most frequently reported AEs were dyspnea, deterioration in COPD, nasopharyngitis, oropharyngeal pain, and increase in blood glucose (Table S1).

Most AEs for both treatments were mild or moderate in intensity; further details are available in the Supplementary materials. Three AEs were classified as SAEs: one patient treated with IND/GLY who experienced two individual SAEs (acute respiratory failure and severe COPD exacerbation) discontinued the study; the second patient (treated with placebo) had a COPD exacerbation, which was not believed to be related to the study drug, but the patient discontinued. No patients died during the study.

\section{Discussion}

To our knowledge, this is the first study to investigate the effect of dual bronchodilation on nighttime oxygenation

Table 3 Analysis of lung function parameters

\begin{tabular}{|c|c|c|c|c|}
\hline \multirow[t]{2}{*}{ Lung function parameters } & \multirow{2}{*}{\begin{tabular}{|l|} 
IND/GLY (N=35) \\
LS means (SE) \\
\end{tabular}} & \multirow{2}{*}{\begin{tabular}{|l|} 
Placebo $(\mathbf{N}=34)$ \\
LS means $(\mathrm{SE})$ \\
\end{tabular}} & \multicolumn{2}{|c|}{ Difference IND/GLY-placebo } \\
\hline & & & Estimate $(95 \% \mathrm{Cl})$ & $P$-value \\
\hline $\mathrm{tFEV}_{1}(\mathrm{~L})$ & $1.33(0.04)$ & $1.14(0.05)$ & $0.19(0.08,0.29)$ & 0.0021 \\
\hline FRC (L) & $4.53(0.15)$ & $5.09(0.15)$ & $-0.56(-0.99,-0.12)$ & 0.0141 \\
\hline FVC (L) & $3.17(0.12)$ & $2.60(0.13)$ & $0.57(0.23,0.91)$ & 0.0025 \\
\hline IC (L) & $2.37(0.07)$ & $2.07(0.07)$ & $0.31(0.13,0.49)$ & 0.0022 \\
\hline $\mathrm{RV}(\mathrm{L})$ & $3.59(0.15)$ & $4.22(0.15)$ & $-0.63(-1.06,-0.20)$ & 0.0049 \\
\hline TLC (L) & $6.91(0.13)$ & $7.15(0.14)$ & $-0.25(-0.64,0.14)$ & 0.2001 \\
\hline $\mathrm{DLCO}^{\mathrm{a}}(\mathrm{mmol} / \mathrm{kPa} \times \min )$ & $4.89(0.37)$ & $4.65(0.37)$ & $0.24(-0.14,0.62)$ & 0.1883 \\
\hline $\mathrm{DLCO} / \mathrm{VA}^{\mathrm{a}}(\mathrm{mmol} / \mathrm{kPa} \times \mathrm{min} / \mathrm{L})$ & $0.94(0.05)$ & $0.90(0.06)$ & $0.03(-0.04,0.1 \mathrm{I})$ & 0.3248 \\
\hline
\end{tabular}

Note: a Only measured in patients at Denmark and Norway sites.

Abbreviations: DLCO, diffusing capacity of the lung for carbon monoxide; DLCO/VA, DLCO divided by the alveolar volume; tFEV ${ }_{1}$, trough $F E V_{1}$; FRC, functional residual capacity; IC, inspiratory capacity; IND/GLY, indacaterol/glycopyrronium; LS means, least square means; RV, residual volume; TLC, total lung capacity. 
Table 4 LS means and difference in LS means for symptoms and sleep quality measures after 4 weeks of treatment with IND/GLY or placebo

\begin{tabular}{|c|c|c|c|c|}
\hline \multirow{2}{*}{$\begin{array}{l}\text { Symptoms and sleep quality } \\
\text { measures }\end{array}$} & \multicolumn{2}{|l|}{ LS means } & \multicolumn{2}{|l|}{ LS means $(95 \% \mathrm{Cl})$} \\
\hline & $\begin{array}{l}\text { IND/GLY } \\
(\mathrm{N}=\mathbf{3 5})\end{array}$ & $\begin{array}{l}\text { Placebo } \\
(\mathrm{N}=34)\end{array}$ & $\begin{array}{l}\text { Difference }^{\mathrm{a}} \\
\text { IND/GLY-placebo }\end{array}$ & $P$-value \\
\hline \multicolumn{5}{|l|}{ CAT } \\
\hline Total CAT score & $15.15 \pm 0.75$ & $|7.7| \pm 0.77$ & $-2.56(-4.72,-0.40)$ & 0.0208 \\
\hline \multicolumn{5}{|l|}{ CASIS } \\
\hline Total CASIS score & $15.29 \pm 0.47$ & $|5.3| \pm 0.48$ & $-0.02(-1.03,1.00)$ & 0.9724 \\
\hline \multicolumn{5}{|l|}{ MOS Sleep Scale } \\
\hline Sleep Problems Index I & $21.36(1.66)$ & $24.41(1.66)$ & $-3.05(-7.76,1.67)$ & 0.2006 \\
\hline Sleep Problems Index II & $22.42(1.35)$ & $26.63(1.39)$ & $-4.21(-8.02,-0.40)$ & 0.0315 \\
\hline Sleep Adequacy & $68.78(3.44)$ & $69.17(3.44)$ & $-0.39(-10.27,9.49)$ & 0.9358 \\
\hline Sleep Disturbance Scale & $22.96(1.69)$ & $27.33(1.75)$ & $-4.37(-9.07,0.33)$ & 0.0672 \\
\hline Sleep Quantity (raw score) & $6.61(0.11)$ & $6.58(0.11)$ & $0.03(-0.28,0.34)$ & 0.8302 \\
\hline Somnolence Scale & $25.07(2.24)$ & $26.71(2.24)$ & $-1.64(-8.00,4.73)$ & 0.6088 \\
\hline Snoring scale & $33.26(3.48)$ & $31.50(3.42)$ & $1.76(-8.12,11.65)$ & 0.7218 \\
\hline \multirow[t]{3}{*}{ Short of Breath Scale } & $4.91(2.02)$ & $13.76(2.02)$ & $-8.85(-14.59,-3.1 \mathrm{I})$ & 0.0031 \\
\hline & & & \multicolumn{2}{|c|}{ OR (IND/GLY/placebo) } \\
\hline & Estimated odds & Estimated odds & Estimate & $P$-value \\
\hline Optimal Sleep Scale & $\mathrm{I} .07$ & 1.02 & $7.79(-4.5 \mathrm{I}, 20.08)$ & 0.2016 \\
\hline
\end{tabular}

Notes: The MOS Sleep Scale, CASIS, and CAT were analyzed according to the mixed model presented with period and treatment as fixed effects, baseline as a covariate effect, and patient as a random effect. The Optimal Sleep Scale (part of the MOS Sleep Scale) was analyzed by a binomial model including period, baseline and actual treatment as fixed effects and patient as a random effect. Values are mean \pm SE unless specified otherwise. 'Only includes patients with data from both treatments.

Abbreviations: CASIS, COPD and Asthma Sleep Impact Scale; CAT, COPD Assessment Test; IND/GLY, indacaterol/glycopyrronium; LS, least squares; MOS, Medical Outcomes Study.

and sleep quality in patients with COPD. Sleep quality assessed by the CASIS score and the MOS Sleep Scale improved after 4 weeks of treatment with IND/GLY. Two measures of the MOS Sleep Scale showed significant differences compared with placebo, as did the CAT score and lung function parameters. However, there was no difference in the primary objective, improvement in mean nighttime $\mathrm{SpO}_{2}$ after 4 weeks of IND/GLY treatment compared with placebo, or the secondary objective, improvement in time spent $<90 \%$ in $\mathrm{SpO}_{2}$. A high degree of interindividual variability was seen and we identified individual patients whose overnight oxygenation improved significantly during IND/ GLY treatment; we cannot exclude that this responder pattern corresponds to a specific COPD phenotype.

Patients treated with IND/GLY showed an improvement in scores for CAT, CASIS, and the MOS Sleep Scale measures, Sleep Problems Index I, Sleep Problems Index II, Sleep Adequacy, Sleep Disturbance Scale, Somnolence Scale, and Short of Breath Scale. The findings were significantly different to placebo for CAT score, Sleep Problems Index II, and Short of Breath Scale. Neither of the previous studies of the effect of bronchodilation on sleep quality showed similar improvements in sleep quality by the measures used in those studies. ${ }^{18,19}$ In the tiotropium study, sleep quality was assessed by polysomnography, information from the patient diary, and sleepiness by the ESS, with no significant difference to placebo for any measure. ${ }^{18}$ In the salmeterol study, sleep quality was measured using polysomnography and sleepiness by the ESS; similarly to the tiotropium study, there was no difference between the active treatment and placebo. ${ }^{19}$ Treatment with IND/GLY significantly improved lung function parameters, indicating both bronchodilatory effects and a reduction of hyperinflation. These findings are consistent with previously reported positive effects of IND/GLY on lung function. ${ }^{20-22}$

Past studies of bronchodilators in COPD showed a positive effect on nighttime oxygenation. Patients treated with the LAMA, tiotropium, showed significant improvements in sleeping arterial $\mathrm{SaO}_{2}$ compared with placebo, with tiotropium in particular during REM sleep. ${ }^{18}$ Similarly, patients treated with the LABA, salmeterol, showed an improvement in both $\mathrm{SaO}_{2}$ and the percentage of sleep spent $<90 \%$ in patients with COPD compared with placebo. ${ }^{19}$ There are some possible explanations for the difference between our results and those reported previously. ${ }^{18,19}$ Unlike previous studies, our study used respiratory polygraphy, 
not polysomnography. Sleep induces alterations in gas exchange with the normal ventilatory response to hypoxia and hypercapnia being reduced in those who are asleep, compared with those who are awake. ${ }^{11}$ The patients in our study may have had less total sleep time during the placebo period, compared with the active treatment period; this is supported by the reporting of more nighttime symptoms with placebo and worse lung function, compared with active treatment. If this is the case, the hypoxemia occurring during sleep in subjects receiving placebo could be underscored by a time dilution factor, by using both true sleep and periods of unnoticed wakefulness as the denominator. This suggests that the gas exchange in patients being treated with placebo is likely to have been similar to the active treatment, because humans breathe more when they are awake. We speculate that the lack of improvement in oxygenation corresponding to the improvement in lung function with active treatment may be related to the selection criteria for the patient group and/or to the relative proportions of wake and sleep time. Unfortunately, respiratory polygraphy does not provide details on sleep architecture, and it is therefore not possible to exclude periods of wakefulness not reported actively from the participants. A second factor which may have influenced our results is differences in COPD severity of our patient cohort compared with those reported previously. In our study, the mean $\mathrm{FEV}_{1}$ was $1.34 \mathrm{~L}$, whereas mean $\mathrm{FEV}_{1}$ was $0.84 \mathrm{~L}$ in the tiotropium study ${ }^{18}$ and median $\mathrm{FEV}_{1}$ was $0.91 \mathrm{~L}$ in the salmeterol study. ${ }^{19}$ We hypothesize that the use of the dual bronchodilator in the milder COPD patients included in our small study, who might also have milder sleep impairment, may have limited the possibility of reaching a significant improvement in overnight oxygenation.

Strengths of our study include the randomized controlled trial design with rigorous measurement of nighttime oxygenation, which took place over two consecutive nights at the beginning and end of each treatment period with a washout period in between. Furthermore, the same trained polygraphy expert, who was blinded to patient information, documented the $\mathrm{SpO}_{2}$ results for each patient. Furthermore, we used well-validated tools for the measurement of symptoms and sleep quality. ${ }^{7,28,29}$ A crossover design, rather than parallel group, was chosen for this study because it was expected that within-patient variability for the parameters assessed in this study would be less than between-patient variability, allowing the required power to be achieved while exposing a smaller number of patients to study treatment. The final analysis set consisted of 38 patients which was greater than that estimated to maintain $80 \%$ power $(n=26)$.
A limitation of the study design may be the use of respiratory polygraphy instead of polysomnography. However, polygraphy can be performed at home in the natural environment, instead of overnight hospitalization. Furthermore, it should be noted also that the previous studies using polysomnography did not detect any differences in sleep quality. A further limitation is that a large number of patients had high oxygenation saturation; however, this was addressed in a post hoc analysis and found not to change the interpretation of the data. Furthermore, selecting patients with moderate-to-severe COPD with mild resting hypoxemia may limit the generalization of the results of the study.

\section{Conclusion}

In conclusion, our study has shown that IND/GLY improves symptoms and sleep quality and confirms previous findings with regard to improvement in lung function. Contrary to our hypothesis, IND/GLY had no effect on nighttime oxygenation which - at least in part - may be explained by the lack of control for actual sleep time in polygraphic recordings. Therefore, our recommendation is that polysomnography should be considered in future studies to clarify further the benefits of bronchodilators on sleep-related oxygenation in patients with moderate-to-severe COPD.

\section{Data sharing statement}

Novartis is committed to sharing with qualified external researchers, access to patient-level data and supporting clinical documents from eligible studies. These requests are reviewed and approved by an independent review panel on the basis of scientific merit. All data provided is anonymized to respect the privacy of patients who have participated in the trial in line with applicable laws and regulations.

\section{Acknowledgments}

This study was funded by Novartis Sverige AB, Sweden. The authors acknowledge the support of Christer Janson, Jorgen Vestbo, and Espen Burum-Auensen and thank Cathy McDonnell (Novartis Product Lifecycle Services, Dublin, Ireland) for providing medical writing support, which was funded by Novartis Sverige AB, Sweden.

\section{Disclosure}

Dr Lehmann reports fees to employer and other support from Novartis, during the conduct of the study. Dr Løkke reports, other than from Novartis during the conduct of the study, personal fees and nonfinancial support from AstraZeneca; grants, personal fees, and nonfinancial support from 
Boehringer Ingelheim; personal fees and nonfinancial support from GlaxoSmithKline; personal fees and nonfinancial support from Novartis; personal fees and nonfinancial support from Chiesi; and grants, personal fees, and nonfinancial support from Pfizer, outside the submitted work. The institution of Dr Grote received payments under the clinical trial agreement with Novartis during the conduct of the study. Dr Hedner reports no financial conflict of interest; he has one patent related to pharmacological therapy in sleep apnea pending and one issued. The authors report no other conflicts of interest in this work.

\section{References}

1. Gao Y, Guan W, Xu G, et al. Sleep disturbances and health-related quality of life in adults with steady-state bronchiectasis. PLoS One. 2014;9(7):e102970.

2. McNicholas WT. Impact of sleep in COPD. Chest. 2000;117(2 Suppl): 48S-53S.

3. McNicholas WT, Verbraecken J, Marin JM. Sleep disorders in COPD: the forgotten dimension. Eur Respir Rev. 2013;22(129):365-375.

4. Cormick W, Olson LG, Hensley MJ, Saunders NA. Nocturnal hypoxaemia and quality of sleep in patients with chronic obstructive lung disease. Thorax. 1986;41(11):846-854.

5. Agusti A, Hedner J, Marin JM, Barbé F, Cazzola M, Rennard S. Nighttime symptoms: a forgotten dimension of COPD. Eur Respir Rev. 2011;20(121):183-194.

6. Stephenson JJ, Cai Q, Mocarski M, Tan H, Doshi JA, Sullivan SD. Impact and factors associated with nighttime and early morning symptoms among patients with chronic obstructive pulmonary disease. Int J Chron Obstruct Pulmon Dis. 2015;10:577-586.

7. Pokrzywinski RF, Meads DM, McKenna SP, Glendenning GA, Revicki DA. Development and psychometric assessment of the COPD and Asthma Sleep Impact Scale (CASIS). Health Qual Life Outcomes. 2009;7:98.

8. Zeidler MR, Martin JL, Kleerup EC, et al; SPIROMICS Research Group. Sleep disruption as a predictor of quality of life among patients in the subpopulations and intermediate outcome measures in COPD study (SPIROMICS). Sleep. 2018;41(5):1-8.

9. Marrone O, Salvaggio A, Insalaco G. Respiratory disorders during sleep in chronic obstructive pulmonary disease. Int J Chron Obstruct Pulmon Dis. 2006;1(4):363-372.

10. Lacasse Y, Sériès F, Vujovic-Zotovic N, et al. Evaluating nocturnal oxygen desaturation in COPD-revised. Respir Med. 2011;105(9): 1331-1337.

11. Gay PC. Chronic obstructive pulmonary disease and sleep. Respir Care. 2004;49(1):39-51.

12. Hudgel DW, Devadatta P. Decrease in functional residual capacity during sleep in normal humans. J Appl Physiol Respir Environ Exerc Physiol. 1984;57(5):1319-1322.

13. Hudgel DW, Martin RJ, Capehart M, Johnson B, Hill P. Contribution of hypoventilation to sleep oxygen desaturation in chronic obstructive pulmonary disease. J Appl Physiol Respir Environ Exerc Physiol. 1983;55(3):669-677.
14. Block AJ, Boysen PG, Wynne JW. The origins of cor pulmonale; a hypothesis. Chest. 1979;75(2):109-110.

15. Flenley DC. Clinical hypoxia: causes, consequences, and correction. Lancet. 1978;1(8063):542-546.

16. Lacasse $\mathrm{Y}$, Bernard $\mathrm{S}$, Sériès $\mathrm{F}$, et al; International Nocturnal Oxygen (INOX) Research Group. Multi-center, randomized, placebo-controlled trial of nocturnal oxygen therapy in chronic obstructive pulmonary disease: a study protocol for the INOX trial. BMC Pulm Med. 2017;17(1):8.

17. Sergi M, Rizzi M, Andreoli A, Pecis M, Bruschi C, Fanfulla F. Are COPD patients with nocturnal REM sleep-related desaturations more prone to developing chronic respiratory failure requiring long-term oxygen therapy? Respiration. 2002;69(2):117-122.

18. McNicholas WT, Calverley PM, Lee A, Edwards JC; Tiotropium Sleep Study in COPD Investigators. Long-acting inhaled anticholinergic therapy improves sleeping oxygen saturation in COPD. Eur Respir J. 2004;23(6):825-831.

19. Ryan S, Doherty LS, Rock C, Nolan GM, McNicholas WT. Effects of salmeterol on sleeping oxygen saturation in chronic obstructive pulmonary disease. Respiration. 2010;79(6):475-481.

20. Bateman ED, Ferguson GT, Barnes N, et al. Dual bronchodilation with QVA149 versus single bronchodilator therapy: the SHINE study. Eur Respir J. 2013;42(6):1484-1494.

21. Wedzicha JA, Decramer M, Ficker JH, et al. Analysis of chronic obstructive pulmonary disease exacerbations with the dual bronchodilator QVA149 compared with glycopyrronium and tiotropium (SPARK): a randomised, double-blind, parallel-group study. Lancet Respir Med. 2013;1(3):199-209.

22. Vogelmeier CF, Bateman ED, Pallante J, Alagappan VK, D'Andrea P, Chen H, Banerji D. Efficacy and safety of once-daily QVA149 compared with twice-daily salmeterol-fluticasone in patients with chronic obstructive pulmonary disease (ILLUMINATE): a randomised, doubleblind, parallel group study. Lancet Respir Med. 2013;1(1):51-60.

23. Wedzicha JA, Banerji D, Chapman KR, et al; FLAME Investigators. Indacaterol-glycopyrronium versus salmeterol-fluticasone for COPD. N Engl J Med. 2016;374(23):2222-2234.

24. Hays RD, Stewart A. Sleep measures. In: Stewart AL, Ware JE, editors. Measuring Function and Well-Being. The Medical Outcomes Study Approach. Durham, NC: Duke University Press; 1992:235-259.

25. Jones PW, Harding G, Berry P, Wiklund I, Chen WH, Kline Leidy N. Development and first validation of the COPD Assessment Test. Eur Respir J. 2009;34(3):648-654.

26. Macintyre N, Crapo RO, Viegi G, et al. Standardisation of the single-breath determination of carbon monoxide uptake in the lung. Eur Respir J. 2005;26(4):720-735.

27. Wanger J, Clausen JL, Coates A, et al. Standardisation of the measurement of lung volumes. Eur Respir J. 2005;26(3):511-522.

28. American Psychiatric Association. American Psychiatric Association, Diagnostic and Statistical Manual of Mental Disorders. Washington, DC: American Psychiatric Association; 1994.

29. Global Initiative for Chronic Obstructive Lung Disease. Global Strategy for the Diagnosis, Management, and Prevention of Chronic Obstructive Pulmonary Disease (2018 Report); 2018. Available from: www. goldcopd.org. Accessed December 11, 2018. 


\section{Supplementary materials \\ Methods}

Study design

Exclusion and inclusion criteria

Patients eligible for inclusion in the study fulfilled all of the following criteria:

- Written informed consent obtained before any assessment was carried out;

- Male or female adults aged $\geq 40$ years;

- Resting daytime oxygen saturation levels measured by pulse oximetry of $\leq 95 \%$ blood oxygen saturation $\left(\mathrm{SpO}_{2}\right)$;

- Patients with a post-bronchodilator $\mathrm{FEV}_{1} \geq 30 \%$ and $<60 \%$ of the predicted normal value;

- Clinical diagnosis of COPD (according to GOLD guidelines, 2014 ${ }^{1}$ ) with a post-bronchodilator $\mathrm{FEV}_{1} /$ FVC $<0.70$; and

- Current or ex-smokers who have a smoking history of at least 10 pack-years (10 pack-years are defined as 20 cigarettes a day for 10 years, or 10 cigarettes a day for 20 years).

Patients fulfilling any of the following criteria were not eligible for the inclusion in the study:

- Women of childbearing potential not using contraception method(s), as well as women who were breastfeeding;

- Ongoing/planned rehabilitation during the study period;

- An exacerbation of COPD (treatment with oral or parenteral antibiotics and/or glucocorticosteroids and/or hospitalization related to COPD) within 4 weeks before screening or during the run-in period;

- Use of oral or systemic glucocorticosteroids within 4 weeks before screening or during the run-in period;

- Three or more awakenings during the night leading to toilet visit or other reasons for exiting the bed during the last week before the screening visit for non-COPD reasons (morning toilet visit not included);

- Respiratory tract infection in the 4 weeks before screening or during the run-in period;

- Body mass index $>32$;

- Diagnosed asthma;

- Malignancy of any organ system (except localized basal cell carcinoma of the skin);

- Diabetes mellitus requiring insulin;

- Long QT syndrome or QTc $>450 \mathrm{~ms}$ (males) or $470 \mathrm{~ms}$ (females);

- Severe renal impairment(glomerular filtration rate: $\leq 30 \mathrm{~mL} /$ $\left.\min / 1.73 \mathrm{~m}^{2}\right)$;

- Patients receiving regular long-term oxygen therapy;
- Known sleep apnea ( $\geq 15$ apneas or hypopneas per hour of sleep) or who have or have had previous bilevel positive airway pressure or continuous positive airway pressure therapy for sleep apnea;

- Symptomatic urinary outflow obstruction;

- Shift workers (or other external conditions affecting sleep and sleep quality on a regular basis);

- Narrow-angle glaucoma;

- Hypersensitivity to any of the ingredients of the investigational therapy;

- Unstable (based upon the investigator evaluation) cardiovascular disease;

- Use of nonselective $\beta$-blockers, including eye drops (cautious use of cardio selective $\beta$-blocking agents is allowed at the discretion of the investigator); and

- Use of anticholinergic medications (except from study treatment).

\section{Results}

\section{Safety outcomes}

Table SI Most frequently reported AEs (at least I\% incidence; safety set)

\begin{tabular}{|c|c|c|}
\hline Adverse events & IND/GLY $(\mathbf{N}=35)$ & Placebo $(\mathbf{N}=34)$ \\
\hline Patients with at least one $\mathrm{AE}$ & $14(40.0 \%)$ & $13(38.2 \%)$ \\
\hline Dyspnea & $5(14.3 \%) 5$ & $4(11.8 \%) 4$ \\
\hline COPD exacerbations & $3(8.6 \%) 3$ & $4(11.8 \%) 4$ \\
\hline Nasopharyngitis & $3(8.6 \%) 3$ & $2(5.9 \%) 2$ \\
\hline Oropharyngeal pain & $2(5.7 \%) 2$ & - \\
\hline Fatigue & I (2.9\%) I & I (2.9\%) I \\
\hline Acute respiratory failure & I (2.9\%) I & - \\
\hline Cough & I (2.9\%) I & - \\
\hline Laryngospasm & I (2.9\%) I & - \\
\hline Productive cough & I (2.9\%) I & - \\
\hline Local swelling & I (2.9\%) I & - \\
\hline Pyrexia & | (2.9\%) I & - \\
\hline Arrhythmia & I (2.9\%) I & - \\
\hline Transient blindness & I (2.9\%) I & - \\
\hline Paresthesia & I (2.9\%) I & - \\
\hline Rash & I (2.9\%) I & - \\
\hline Increased blood glucose & - & $2(5.9 \%) 2$ \\
\hline Pulmonary embolism & - & I (2.9\%) I \\
\hline Rhinorrhea & - & I (2.9\%) I \\
\hline Bronchitis & - & I (2.9\%) I \\
\hline Reactive arthritis & - & | (2.9\%) | \\
\hline
\end{tabular}

Notes: $x(x x . x \%) y=$ the number of patients (the percent of patients with at least one $\mathrm{AE}$ ) actual number of AEs. AEs are presented in descending order of frequency in the IND/GLY group.

Abbreviations: AE, adverse event; IND/GLY, indacaterol/glycopyrronium. 


\section{Intensity of adverse events}

While most adverse events were mild to moderate in intensity, five severe AEs were reported. Two patients treated with IND/GLY reported three severe AEs: acute respiratory failure and COPD exacerbation, both assessed as related to the study drug; and transient blindness, assessed as not related. Two patients reported one severe $\mathrm{AE}$ each while being treated with placebo (both COPD exacerbations: one assessed as related to the study drug, and the other not related).

\section{Reference}

1. Global Initiative for Chronic Obstructive Lung Disease. Global strategy for the diagnosis, management, and prevention of chronic obstructive pulmonary disease; 2014. Available from: http://www.goldcopd.org/uploads/ users/files/GOLD_Report_2014_Jun11.pdf. Accessed December 5, 2018

\section{Publish your work in this journal}

The International Journal of COPD is an international, peer-reviewed journal of therapeutics and pharmacology focusing on concise rapid reporting of clinical studies and reviews in COPD. Special focus is given to the pathophysiological processes underlying the disease, intervention programs, patient focused education, and self management protocols.
This journal is indexed on PubMed Central, MedLine and CAS. The manuscript management system is completely online and includes a very quick and fair peer-review system, which is all easy to use. Visit http://www.dovepress.com/testimonials.php to read real quotes from published authors. 